\title{
Dos livros, da leitura, da literatura, Entrevista com o professor Clóvis Da Rolt
}

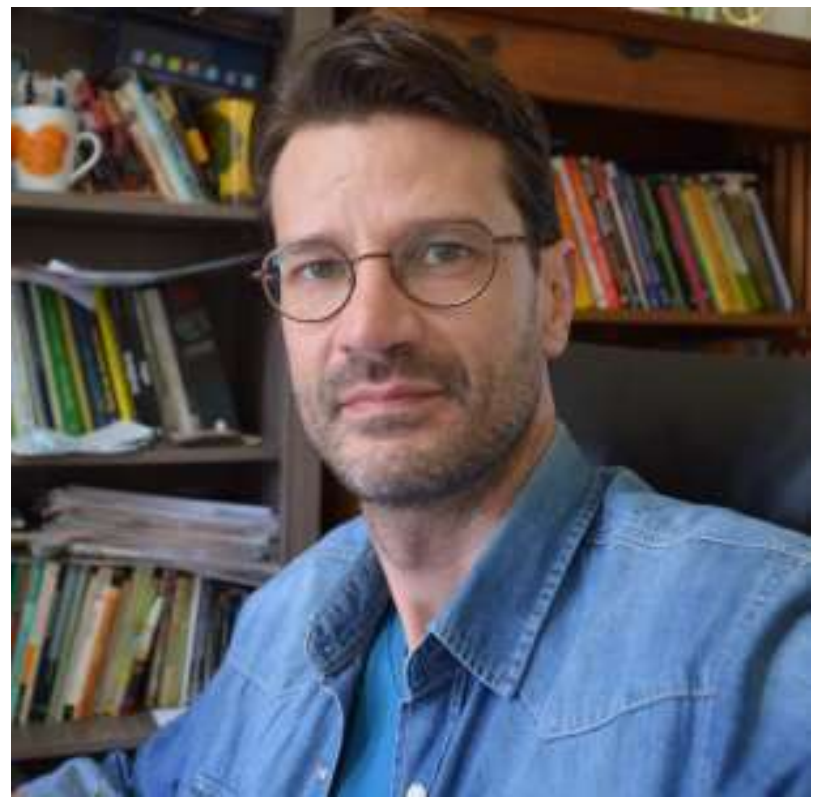

Docente na Universidade Federal do Pampa (UNIPAMPA), Campus Jaguarão-RS. Possui graduação em Licenciatura Plena em Artes Plásticas (Universidade de Caxias do Sul), Especialização em Ética e Filosofia Política (Universidade de Caxias do Sul), Mestrado em Ciências Sociais (Universidade do Vale do Rio dos Sinos) e Doutorado em Ciências

Sociais (Universidade do Vale do Rio dos Sinos). Realizou período de estudos de doutorado na Faculdade de Belas Artes da Universidade de Granada (Espanha), mediante bolsa do Programa de Formação Permanente da Fundación Carolina e Junta de Andaluzia.

Atua no campo das Artes Visuais e da Antropologia com especial interesse nos seguintes temas: história e teoria das artes visuais, arte-educação, antropologia cultural e estudos do imaginário.

Dialogia: Poderia elaborar um breve relato de seu percurso profissional?

Clóvis Da Rolt: Comecei a trabalhar muito cedo, aos quatorze anos de idade. Após diversas experiências profissionais, concluí o curso de Licenciatura em Artes Plásticas, o que me levou a atuar com arte-educação (em escola, curso técnico e casa de cultura). Alguns anos depois, ingressei numa especialização em Filosofia e prossegui os estudos com o mestrado e o doutorado em Ciências Sociais. Por algum tempo fui também colunista de um jornal na minha cidade natal, Bento Gonçalves-RS. Atualmente, sou professor da Universidade 
Federal do Pampa (UNIPAMPA) - Câmpus Jaguarão-RS, onde leciono disciplinas no campo da arte e da antropologia.

No que concerne à literatura, publiquei um livro de poemas em 2004, Canção de vidro. Em 2006, como integrante de um grupo, surgiu a coletânea Calendário - Antologia poética do Grupo Neblina. Após um hiato, em 2014 publiquei um livreto-experimento intitulado Universo. Em 2016 saiu meu trabalho mais recente em poesia, o livro $A$ orientação das serpentes, que foi finalista do Prêmio Açorianos de Literatura (Porto Alegre-RS).

\section{Dialogia: As bibliotecas passam por grandes transformações. Qual sua posição diante das mudanças? Quais gostaria de destacar?}

Clóvis Da Rolt: Creio que há mudanças salutares, como aquelas que olham com mais atenção para os leitores com necessidades especiais e para as novas plataformas de leitura. Vale destacar também a atenção que algumas bibliotecas têm dado à formação de leitores, especialmente em relação às crianças, já que este público, quando exposto a uma formação leitora qualificada, pode representar a continuidade de algumas propostas futuras.

Acho interessantes as iniciativas de algumas bibliotecas que operam numa lógica de convergência, ou seja, que constroem espaços para múltiplas experiências culturais e de sociabilidade. Penso, por exemplo, em bibliotecas que não acolhem exclusivamente a cultura escrita, mas também oferecem aos frequentadores espaços como galerias de arte, salas de cinema, filmotecas, ciclos de palestras, cursos diversos, etc.

Parece-me que a nossa época apresenta uma tendência à convergência, no sentido de que se possa extrair o máximo de experiências de um único contexto/lugar. Todavia, mesmo que uma biblioteca esteja formatada como um espaço supertecnológico, multissensorial e diversificado em seu repertório de "serviços", a leitura segue sendo algo muito pessoal: a elaboração íntima de um sujeito que quer se conhecer e conhecer o mundo. Evidentemente, tal elaboração também é possível em espaços mais tradicionais, dependendo do perfil do leitor.

Em alguns casos, devido à ânsia de atualização operada por modismos, há bibliotecas demasiadamente preocupadas com uma cosmética espacial e com a criação de uma atmosfera "descolada" e agradável aos leitores, o que pode gerar uma noção de que a leitura é sempre fácil, blasé e prazerosa como uma ida ao shopping center. Ler, ler verdadeiramente, ler em profundidade, ler com entrega e afinco é um aprendizado que vem com o tempo, instala-se aos poucos, cria camadas de aprimoramento. Isso nem sempre é 
prazeroso e agradável. É para o implemento deste aprendizado que as bibliotecas devem nos auxiliar.

\section{Dialogia: Qual o papel principal das instituições escolares em relação a leituras?}

Clóvis Da Rolt: São muitos os papéis desempenhados pelas instituições escolares no que se refere à leitura, tanto para promovê-la quanto para torná-la algo insuportável e maçante. Grandes paixões pela leitura podem ser construídas na escola. E grandes decepções também. O principal papel, inicialmente, está relacionado a uma alfabetização consistente, na idade certa, capaz de desenvolver ao máximo as competências leitoras dos alunos (leitura do texto, leitura do mundo, leitura de si mesmo no texto e no mundo). Não há leitor verdadeiramente formado que não tenha passado por uma sólida proposta alfabetizadora.

Penso que as escolas devem ser promotoras da leitura. Isso equivale a dizer que elas devem ter bibliotecas frequentadas; investir em metodologias de trabalho que incluam o livro e a leitura no cotidiano dos alunos; oportunizar a formação continuada (para as práticas de leitura) especialmente aos professores das séries iniciais, além de incentivar a percepção da leitura como um investimento precioso que reverbera na construção de imaginários, na capacidade de expressar-se com mais eficiência, na experiência estética da linguagem e no autoconhecimento. Porém, levando em consideração o que tenho observado em relação aos alunos que chegam à universidade, é evidente que a escola não está atuando na formação de leitores (o mesmo vale para a competência escrita). Mas o mais grave é que a escola pode estar corroendo os nossos alunos talentosos e nivelando por baixo os que teriam condições de se destacar.

Precisamos mais do que um fetichismo diante da leitura, mais do que uma encenação piegas sobre o valor histórico e cultural do livro durante a famigerada "Semana do Livro" organizada pela escola. Muitos desses eventos, inclusive, estão completamente esvaziados, haja vista a baixa qualidade do que se oferece aos alunos em termos literários. Projetos como o "autor na escola", via de regra, tornaram-se oportunidades para autores medíocres desovarem sua produção encalhada e lucrarem em cima de inocentes ainda incapazes de separar o joio do trigo. Além disso, são muitos os professores que não têm o hábito da leitura ou que sequer se sentem vexados em admitir que não gostam de ler. Como poderão atuar na formação de novos leitores? 


\section{Dialogia: Diz-se que o Brasil deveria ter mais leitores. Como fazer isso?}

Clóvis Da Rolt: Não creio que a quantidade seja um critério único. Precisamos de um número maior de leitores ou de mais qualidade nos níveis de leitura dos leitores que já temos? Talvez precisemos de ambos, mas isso não será uma tarefa fácil de ser alcançada diante de um país que ainda possui cerca de doze milhões de analfabetos. Se acrescentarmos a este número os analfabetos funcionais e os analfabetos diplomados (sim, o Brasil é um país no qual existe a categoria dos "analfabetos diplomados"), a situação torna-se verdadeiramente caótica.

Sempre acreditei que a leitura, a competência leitora e a formação do leitor são processos difíceis de se enquadrar com precisão. Para aprimorá-los há inúmeras estratégias de fomento, metodologias de ação, formas de incentivo, políticas públicas governamentais, etc. Mas acerca da leitura há também um mistério, algo que costumo associar a uma descoberta, uma revelação, um salto num abismo. Para algumas pessoas este mistério se apresenta, mas não para todas. Mal comparando, é como acreditar no poder e na ação de uma divindade. Chega um ponto em que as catequeses, exegeses e propedêuticas falham: ou você assume o divino ou o descarta. Com a leitura acontece algo semelhante. O mistério não se ensina, se vive. Mais do que teoria, leitura é prática. Quantos estão dispostos a isso?

A leitura é um processo tímido, lento, silencioso. É uma capacidade que vai sendo adquirida e aprimorada mediante a percepção de um tempo interno que varia de leitor para leitor. A leitura exige também a vivência de outras práticas e expressões da cultura e da linguagem que a ela se conectam, como o cinema, a música, o teatro. Isso quer dizer que, através do texto, lemos sempre um mundo em movimento e em conexão com experiências extratextuais.

Acredito que grande parte da formação de um leitor não está necessariamente ligada à escola, ao amparo do Estado, às estratégias de fomento à leitura, à ação de bibliotecas, etc. Tudo isso colabora, mas não é determinante. Ensina-se a técnica, a decodificação de um sistema linguístico, as características de um texto, a estrutura de um romance... Mas não se ensina a emoção, a sedução, a perplexidade, o encantamento e o mistério que fazem parte da leitura. Grande parte de tudo o que envolve a leitura é de natureza estritamente pessoal, é intransferível e intraduzível.

Como país, estamos atrasados em vários aspectos. A leitura é só um deles. Além disso, há pessoas que foram expostas a todos os recursos de incentivo à leitura, estudaram em boas escolas, são vizinhas de uma grande biblioteca, têm tempo disponível, usufruem de 
diferentes experiências culturais... E ainda assim não são leitoras! Se todas as condições favoráveis lhes foram possibilitadas, por que não leem?

\section{Dialogia: Como vê as relações entre Educação e Literatura?}

Clóvis Da Rolt: São relações necessárias, fundamentais e imprescindíveis. Não há educação que possa relegar a literatura a um plano acessório. Uma educação que não contemple a literatura não merece ser qualificada como tal. A literatura constitui um grande arquivo da memória, da expressão simbólica e da sensibilidade humana; é um dos principais meios de entendimento do drama que é a existência. Sem a literatura perdemos um dos meios fundamentais de representação acerca de quem somos nós, além de empobrecermos os sentidos que podemos dar à vida.

Nas tradições antigas, o estudo aprofundado da literatura, da poesia e da linguagem (retórica, gramática, lógica, etc) era condição mínima de civilidade, além de constituir um caminho obrigatório a ser trilhado para uma formação intelectual. Hoje, lamentavelmente, há um movimento de repúdio aos clássicos e às tradições. Falar em "literatura superior" tornou-se ofensivo. Há toda uma militância relativista e desconstrucionista que quer nos fazer acreditar que não existem diferenças entre um poema de Virgílio e a letra de uma canção sertaneja, já que tudo é "expressão" e como tal deve ser entendido. Com isso, estamos legitimando o grotesco e o banal, pois eles também "expressam" alguma coisa. A barbárie cultural mais comezinha tem ocupado um lugar que outrora pertenceu aos gigantes.

Escritores, poetas, artistas, filósofos, bibliófilos e pensadores consagrados disputam hoje espaço com youtubers e "influenciadores digitais", gente que ganha a vida hipnotizando as massas com sofismas, chistes e alguns insights ocasionais. Nesse sentido, penso ser necessário criarmos algumas formas de blindagem, as quais só serão eficazes quando os clássicos voltarem a ser novamente uma presença fundamental frente aos processos de formação e educação. 